\title{
Relaciones laborales ¿Una realidad estructural, coyuntural o un perjuicio instaurado a nivel mundial?
}

\author{
Bayón Pérez, Jessica ${ }^{1}$ \\ Arenas Falótico, Andrés Jerónimo²
}

\section{Resumen}

En un mundo globalizado, en constante cambio, por un lado, los países europeos con gobiernos estables que desarrollan e implementan iniciativas que potencien un cambio socioeconómico, mejore las condiciones de vida de la ciudadanía y formulan nuevos proyectos de ayuda intracomunitaria. Por otro lado, la inseguridad laboral, inestabilidad y precariedad en las relaciones laborales en Latinoamérica consagran una llamada a la reformulación, al cambio positivo y conversión de las relaciones laborales y de la búsqueda de gobiernos con mayores niveles de estabilidad, compromiso y sensibilización con las lagunas de un sistema legislativo laboral "eficiente". El objetivo de este artículo académico es analizar las diferentes políticas laborales, realizar una comparación entre la UE y los países latinoamericanos para poder puntualizar qué se está desarrollando de forma eficiente y en qué se puede mejorar. La metodología es descriptiva permitiendo estudiar la realidad de las relaciones laborales y sus características fundamentales. Los resultados obtenidos, forma genérica, cuentan con los mismos dilemas a diferentes niveles de impacto: Flexibilidad laboral a través de contratos temporales, escasa seguridad laboral, elevado desempleo joven, políticas socioeconómicas ineficaces e

Recibido: 20.03.19 Aceptado: 20.06.19

1 Doctora en Ciencias Sociales con especialidad en Recursos Humanos. Universidad de Nebrija- España. Recientemente galardonada con la Medalla de Oro al Mérito del Trabajo por la Asociación Europea de Economía y Competitividad. Trayectoria profesional enfocada en Recursos Humanos en el ámbito Sociosanitario. Mejor expediente académico del Grado en Relaciones Laborales y Recursos Humanos. Trayectoria en diferentes Universidades en el ámbito Jurídico y Recursos Humanos. E-mail: jbayon@nebrija. es; ORCID: https://orcid.org/0000-0003-4019-7605²

2 Doctor en Management, Máster en Educación y Dirección y Gestión de Empresas (MBA por sus siglas en inglés), Abogado y Periodista. Amplia experiencia en el área de las tecnologías de la información y comunicación. Experto en Sistemas de Comunicación satelital y de radio. Ha recibido premios por su calidad docente tanto nacional como internacionalmente. Ha trabajado en empresas multinacionales y desempeña docencia en la Universidad Antonio de Nebrija, España. E-mail: aarenas@nebrija.es ; ORCID: https://orcid. org/0000-0002-2763-9707 
Relaciones laborales ¿Una realidad estructural, coyuntural o un perjuicio instaurado a nivel mundial?

Bayón Pérez, Jessica y Arenas Falótico, Andrés Jerónimo

ineficientes y decisiones implantadas con resultados no fructíferos ¿Nos encontramos ante un laberinto sin salida?; ¿Los poderes públicos que confluyen todo el poder no tienen la capacidad ni el interés en trasladar cambios a nivel empresarial y jurídico? $\mathrm{O}$ ¿Las medidas adoptadas son un conjunto de parches predispuestos sobre grandes heridas abiertas? Todas estas cuestiones respaldan las conclusiones mencionadas anteriormente. Esta es una visión mundial, a grandes rasgos, donde parece no existir una política clara y efectiva que logre empleos estables, seguros e indefinidos.

Palabras clave: Relaciones laborales; contratos; Latinoamérica; Unión Europea; políticas sociolaborales.

\title{
Labor relations $A$ structural, cyclical reality or a damage established worldwide?
}

\begin{abstract}
In a globalized world, constantly changing, on these side European countries with stable governments that develop and implement initiatives that promote socio-economic changes, improve the living conditions of citizens and formulate new projects of intracommunity support. On the other hand, job insecurity, instability and precariousness in labor relations in Latin America consecrate a call for reformulation, positive change and conversion of labor relations and the search for governments with greater levels of stability, commitment and awareness with the lacunae of an "efficient" labor legislative system. The objective of this academic article is to analyze the different labor policies, make a comparison between the EU and the Latin American countries in order to be able to specify what is being developed efficiently and what can be improved. The results obtained, generically, have the same dilemmas at different levels of impact: Labor flexibility through temporary contracts, poor job security, high youth unemployment, inefficient and inefficient socioeconomic policies and decisions implemented with unsuccessful results. Is this a labyrinth without exit? Do the public authorities that bring together all the power have the capacity or the interest to transfer changes at the business and legal level? Or are the measures adopted a set of predisposed patches on large open wounds? All these issues support the conclusions mentioned above. This is a global vision, in broad senses, where there seems to be no clear and effective policy that achieves stable, secure and indefinite jobs.
\end{abstract}

Keywords: Labor relations; contracts; Latin America; European Union; socio-labor policies. 


\section{1.- Introducción}

A nivel mundial y especialmente en América Latina ha habido en las últimas décadas un incremento en las formas atípicas de empleo (Organización Internacional del Trabajo, 2016). Ello ha estado asociado a los cambios y evoluciones de las nuevas tecnologías que han provocado alteraciones $y$ transformaciones impactantes a nivel laboral, a la búsqueda de mayor flexibilidad laboral, a la implementación de nuevas formas de organización industrial y a la potenciación del acceso e incorporación constante de la mujer al mercado de trabajo.

Sin embargo, y paralelamente, durante el último decenio América Latina ha venido experimentado un proceso de avance en el marco de las relaciones laborales. Ello se evidencia en la reducción de la tasa de desempleo, la creación de nuevos puestos de trabajo, el incremento del salario medio real y la formalización del empleo (Thomson Reuters, 2018). No obstante, a pesar de estas evoluciones, los países latinoamericanos siguen evidenciando déficits importantes en materia laboral. La elevada incidencia de la informalidad resulta ser una fuente de bajos salarios, de falta de cobertura de la seguridad social y también de inestabilidad laboral (Moraes, M.I \& Thul F., 2017). Sin embargo, aún dentro de la formalidad, la prevalencia de contratos temporales resulta significativa con consecuencias semejantes, en algunos casos, a las de una ocupación informal. Al mismo tiempo, para algunos conjuntos de trabajadores, el empleo a media jornada es la forma más frecuente de inserción laboral (Manky, 2017).

En abundancia se razonan y analizan las causas, el rol e impacto de estas formas atípicas de empleo. Por un lado, se ha planteado que estas formas más flexibles de empleo, especialmente los empleos temporales, podrían ser un paliativo frente a las elevadas tasas de desempleo, especialmente en algunos países europeos. Desde el año 2012, han destacado en este problema estructural España y Grecia con respecto a los demás (Diario Oficial de la Unión Europea, 2018). Se sugiere, asimismo, que estos empleos pueden ser un "stepping stone" para acceder a otros de mejor calidad en el futuro, donde el empleador emplee estos contratos como un período de prueba o screening para evaluar y valorar la productividad de las personas y la correspondencia entre sus características y las de la ocupación previas a proceder la conversión de este puesto en otro a tiempo indefinido o indeterminado (Guerrero, L.P., 2018).

Sin embargo, los modos irregulares o poco comunes de empleo podrían generar segmentación en el mercado de trabajo donde los trabajadores con contratos permanentes o full-time reciben mayores salarios, mayor flexibilidad horaria y destacadas condiciones de trabajo que aquellos con similares características pero que tienen contratos temporales o part-time. Por otro lado, frente a estas nuevas modalidades de contratación podría darse una sustitución del empleo indefinido por los contratos temporales que podrían desembocar un incremento en las tasas globales de salida empresarial desde la ocupación efectiva y, consecuentemente, un notable aumento al desempleo (Ministerio de Trabajo, Migraciones y Seguridad Social, 2019).

La estabilidad en el puesto de trabajo es una de las diferencias más evidentes entre los contratos a tiempo fijo e indefinido, no sólo debido a la 
Relaciones laborales ¿Una realidad estructural, coyuntural o un perjuicio instaurado a nivel mundial?

Bayón Pérez, Jessica y Arenas Falótico, Andrés Jerónimo

finalización prevista en los primeros sino porque durante los ciclos económicos afectan considerablemente en las tipologías de creaciones contractuales para alcanzar el ajuste del personal que suele recaer mayormente sobre éstos debido a la posibilidad de modificación, destrucción, amortización, etc. De las relaciones laborales. Al mismo tiempo, las personas que estén ocupadas en la modalidad de larga duración tienen, en general, mayor acceso a una formación integral y efectiva en el puesto de trabajo que aquellos de duración determinada, lo que también puede afectar considerablemente y de forma directa en una mayor estabilidad.

Particularmente, el empleo a tiempo parcial, en ciertos contextos y para ciertos grupos, éstos podrían ser una forma o posibilidad de inserción que permite combinar el empleo con otras laborales formativas, lúdicas, cuidado de hijos menores o personas dependientes, etc.

Por tanto, se puede confirmar con el análisis, estudio y profundización de las diferentes políticas de empleo que existe una mayor inestabilidad y desprotección de la ciudadanía iberoamericana con respecto a Europa.

La metodología que se ha seguido es el estudio del mercado de trabajo tanto de la Unión Europea como de los países latinoamericanos a través del análisis de datos de la población en relación con tipos de contrato desarrollados, duración de los empleos, estudio de la legislación de diferentes países para poder analizar de qué forma se potencian determinados tipos de relaciones laborales. Es por ello, que se emplea una metodología descriptiva que ha permitido estudiar la realidad de las relaciones laborales y sus características fundamentales. La hipótesis queda totalmente contrastada pues el fomento de la precariedad laboral, contrataciones temporales, salarios inseguros e inestables, etc. Es suficiente para reflejar las ineficaces políticas sociolaborales implantadas hasta ahora.

\section{2.- Situación de Partida. Características de las relaciones laborales en la actualidad}

Las formas inusuales de empleo se integran en aquellas ocupaciones que no forman parte de los arreglos laborales estándar; esto es, no se componen de empleos asalariados contratados por el empleador que hace uso directo de la mano de obra, a tiempo completo y de forma indefinida. Por lo tanto, las modalidades no estandarizadas de empleo requieren parches en lo relativo a la jornada laboral, a la estabilidad del puesto de trabajo y/o al tipo de contratación. A continuación, se estudiará cada una de ellas:

a) Organización irregular del tiempo efectivo del trabajo. Se incluyen aquí aquellas elecciones de formalización contractual que difieren de la relación laboral a tiempo completo. No existe una definición internacional de lo que se considera una "semana de trabajo estándar" (Europapress, 2018). Según Europapress nos revela con una clara diferenciación entre países de la Unión Europea. En España, se trabajan más horas (8 horas semanales) que en Alemania, Francia o Inglaterra con una productividad notablemente menor. Asimismo, ocurre en México, Costa Rica, Chile, Rusia con respecto a Alemania, Países Bajos, Noruega, Dinamarca, Luxemburgo, Bélgica, entre otros. Es por ello, que se podría formular la siguiente 
pregunta: ¿Por qué los países con un mayor número de horas trabajadas, con peores salarios y horarios inflexibles no apuestan por políticas públicas similares a países exitosos? Por tanto, la mayoría de los países con baja productividad crean nuevas formas de organización del tiempo de trabajo consideradas anormales donde la duración de la jornada laboral es inferior a la común; en particular, el empleo a tiempo parcial y el empleo por llamada. Este último es un caso extremo que consiste en una necesidad puntual, es decir, el contrato no estipula horas de trabajo, sino que éstas dependen de las necesidades del empleador y de la disponibilidad del trabajador.

\section{b) Contratos atípicos de empleo.}

Se incluyen aquí los empleos que no están enmarcados en contratos a tiempo indefinido. Estas formas temporarias de empleo engloban a los contratos con una duración definida previamente, empleos cuya duración se extiende hasta la finalización de una tarea o de un proyecto, los contratos de prácticas y a los trabajadores jornaleros. En España solo el $8 \%$ de los contratos temporales se convierten en fijos. Desde una mirada europea, los países que mayor tasa de conversión contractual de temporal a indefinido son: Lituania con un 52\%; Estonia con un $38 \%$; Dinamarca con un 29 \%. A la cola de Europa, se puede encontrar Grecia con un $1 \%$, Chipre con un $3 \%$ y Polonia con un $4 \%$ (El país, 2018). Asimismo, los sectores económicos con un mayor nivel de temporalidad son la construcción, agricultura, entretenimiento y hostelería (Eurostat, 2018).

En el año 2018, América Latina y el Caribe creció sólo un 1,9\%. Este impactante resultado se debe a factores estructurales como temporales. Este insignificante crecimiento económico impide desarrollar países productivos donde puedan ofrecer empleos estables, adecuadamente retribuidos $y$ ofrecer una potente responsabilidad social corporativa (Cavallo, E. \& Powell, A., 2018).

c) Relaciones laborales atípicas. Las relaciones laborales típicas son aquellas donde un empleador contrata a un trabajador para desempeñarse por un determinado salario. En contraposición a esta figura, aparecen formas de contratación donde, o bien la condición de asalariado se desdibuja o donde la contratación no se hace de manera directa por parte del empleador que finalmente hace uso de la fuerza de trabajo. Se incluyen aquí, entre otros, a los trabajadores contratados por agencias de empleo o subcontratistas y trabajadores autónomos económicamente dependientes. En los dos primeros casos aparece una relación triangular de empleo donde se terceriza la contratación del personal. En el último caso, son trabajadores independientes que trabajan para uno o pocos clientes con lo cual mantienen una fuerte dependencia económica con ellos, pero que no lo hacen bajo un contrato de empleo. Podría incluirse aquí el trabajo a domicilio.

Además de apartarse de las formas tradicionales de empleo, estos nuevos arreglos pueden implicar mayores riesgos laborales, menor protección y/o salarios menores y más inestables respecto de los asalariados enmarcados en relaciones laborales estándar.

En España, las Empresas de Trabajo Temporal (ETT) son empleadas como vía para la reintegración de desempleados y reducción del paro estructural y son consideradas como el mejor medio para la rápida y eficaz 
Relaciones laborales ¿Una realidad estructural, coyuntural o un perjuicio instaurado a nivel mundial?

Bayón Pérez, Jessica y Arenas Falótico, Andrés Jerónimo

reintegración de colectivos de difícil inserción en el mercado de trabajo. (Tu Europa, 2018).

$\mathrm{Si}$ realizamos un estudio comparado con los programas formales de empleo dirigido a jóvenes están bien extendidos por toda América Latina. Se puede distinguir el programa " 40 mil primeros empleos" en Colombia, "Jóvenes Productivos" en Perú o "Jóvenes con Más y Mejor Trabajo" en Argentina, los gobiernos nacionales buscan desarrollar iniciativas para promover la contratación formal y la adquisición de las adecuadas habilidades y competencias que le permitan acceder y mantenerse en el mercado de trabajo (Hernández, L., 2018). Muy alejado con las cifras de la UE, donde el desempleo juvenil descendió en el año 2018 con un 14,8\%, aunque España sea de los países en la cola de Europa, puesto que el porcentaje de jóvenes menores de 25 años desempleados es del 33,4\% (Europa press, 2018). Aún queda mucho por avanzar tanto en países latinoamericanos donde las oportunidades del mercado laboral no son lo suficientemente benévolas y países de la Unión Europea tales como España y Grecia. Sin embargo, estas dos últimas, gracias a las políticas comunitarias han logrado alcanzar cambios en pro de mejorar las condiciones laborales, salarios, flexibilidad, conciliación laboral y promoción de colectivos con mayor vulnerabilidad para acceder a un empleo como pueden ser jóvenes, personas mayores de 45 años, personas con discapacidad, mujeres víctimas de violencia de género, etc. Donde aún quedan muchos propósitos de concienciación e implementación de políticas directas, eficaces y rentables en países iberoamericanos.

\section{Estudio de la contratación laboral según los distintos países Latinoamericanos y europeos:}

En este apartado, se va a estudiar y analizar cuáles son las diferentes formas contractuales que destacan en los países punteros de cada región.

\section{1.- Contratación Laboral en varios países de Latinoamérica:}

A continuación, se va a implementar un efectivo análisis de países pertenecientes a Latinoamérica.

\subsubsection{Colombia}

Contrato a término fijo 0 de duración determinada: Este es un contrato laboral con una duración temporal especificada de manera clara, directa y concisa. Este puede ser prorrogado indefinidamente, salvo en casos en los cuales el plazo sea previamente pactado y sea inferior a un año, este contrato a término fijo que se puede clasificar de dos formas de contratación, los cuales son: Contrato con un vencimiento inferior a un año y los contratos con una duración igual o superior a un año, las modalidades son:

1.- Tipo de contrato igual o superior a un año: Debe constar siempre por escrito, el término de su duración no puede ser superior a tres años, pero puede ser prorrogable de forma indefinida, y si hay periodo de prueba debe constar por escrito al inicio del contrato. Para su terminación no se requiere aviso previo. En caso de terminación unilateral del contrato sin causa justificada, el empleador deberá 
pagar al trabajador una indemnización según legislación vigente (Lozano, Z.A., 2018).

Si la comparamos con España, ciertamente tiene modalidades contractuales parecidas. Aunque hay que resaltar que es de vital importancia justificar la causa para celebrar un contrato temporal, es decir, no es legal la concatenación de contratos temporales, ya que, desde el impulso de la UE, se trata de potenciar los empleos indefinidos. Es por ello, que existe el contrato de obra o servicio determinado, en el cual, la duración puede ser de uno a tres años prorrogable a un año más por convenio colectivo. Se especifica que debe estar especificada la actividad y no debe guardar ninguna relación con la actividad habitual de la empresa. En este sentido hay una mayor protección de los empleados, pues a pesar de la infinidad de estrategias empresariales por reducir costes contractuales, la Ley es clara y específica y en caso de demanda tanto las empresas privadas como las administraciones públicas serán juzgadas según los términos legalmente establecidos.

Por otro lado, también existe el contrato eventual por circunstancias de la producción. Este contrato está legalmente justificado cuando haya una necesidad temporal debido al aumento de la actividad normal de la empresa. En este caso su duración mínima es de seis meses dentro del periodo de un año, aunque existen excepciones de acuerdo con los convenios colectivos que regulan su actividad.

Igualmente, en el ordenamiento jurídico español protege a ambas partes tanto al empresario como al empleado en caso de extinción del contrato de forma unilateral siempre habrá de realizar un previo aviso de 15 días dependiendo del contrato de trabajo y convenio regulador. En caso contrario ambas partes pagarán una indemnización por aquellos días dejados de avisar.

2.- Modalidad Inferior a un año: Este tipo de contratos únicamente pueden prorrogarse hasta tres veces, por periodos iguales o inferiores, al cabo de los cuales el término de renovación no podrá ser inferior a un año. Para su terminación no se requiere aviso previo. En caso de terminación unilateral del contrato sin una causa justificada, el empleador deberá abonar al trabajador una indemnización de acuerdo a la legislación vigente. (Lozano, Z.A., 2018).

3. Contrato temporal, ocasional o accidental según el Código Sustantivo del Trabajo en Colombia, se define el trabajo ocasional, accidental o transitorio, como aquel trabajo de corta duración y no mayor de un mes, que se refiere a labores distintas de las actividades normales del empleador. Es decir, que no tiene que ver con las labores propias que desarrolla habitualmente el contratante.

Esta forma de contratación cabe hacerse por escrito o verbalmente, si bien siempre se recomienda hacerse por escrito, especificando la tarea del trabajador para evitar conflictos durante y a posteriori de la realización de las labores. Por último, su duración nunca podrá ser mayor a treinta días (González, A.P., 2018).

Desde un punto de vista comunitario, este tipo de contrato estaría fomentando empleos precarios y facilitar la flexibilidad empresarial. De forma genérica en la Unión Europea se trata de paliar no solo el desempleo en sí, sino empleos temporales. En dirección y gestión de Recursos Humanos se potencia el sentido de pertenencia, mejora la productividad, disminuye el absentismo laboral, accidentes de 
Relaciones laborales ¿Una realidad estructural, coyuntural o un perjuicio instaurado a nivel mundial?

Bayón Pérez, Jessica y Arenas Falótico, Andrés Jerónimo

trabajo, bajas por incapacidad temporal, etc.

Estos contratos que se rigen en Colombia son políticas que no permiten forjar un mercado de trabajo implacable en cuanto a forma y contenido.

4. Contratos indefinidos: Son aquellos que no tiene estipulada una fecha de finalización de la obligación contractual, cuya duración no está determinada por la de la obra o la naturaleza de la labor contratada, o no se refiera de manera explícita a un trabajo ocasional o transitorio. Puede hacerse por escrito o de forma verbal, pero si se quieren establecer cláusulas específicas para el contrato es necesario formalizar el contrato a través de un contrato escrito. Además, el empleador se compromete a pagar prestaciones sociales, prima de servicios, descansos remunerados y aportes parafiscales. $Y$ en caso de terminación unilateral del contrato sin una causa justificada, el empleador deberá pagar al trabajador una indemnización conforme a Ley (Europa press, 2018).

En los últimos años, en Europa ha logrado un aumento de los contratos indefinidos multiplicado por cuatro en comparación con la contratación temporal (Europa press, 2018).

5. Contrato civil por prestación de servicios: Este tipo de contrato se celebra de forma bilateral entre una empresa y un trabajador que puede ser natural o jurídica, especializada en alguna labor específica. La remuneración es acordada entre las partes y no conlleva una relación laboral ni obliga a la organización a pagar prestaciones sociales. La duración es igualmente en común acuerdo dependiendo del trabajo a desarrollar. El contratado percibe un ingreso económico, al cual, se le descuenta únicamente por concepto de retención en la fuente (European Comission, 2018).

Desde la Unión Europea ha habido una fuerte política contra el desempleo desde el año 2012. Como consecuencia, se ha impulsado el autoempleo a través de diferentes incentivos que mejoran notablemente las condiciones de los emprendedores (European Comission, 2018). Actualmente, desarrolla el programa 'StartupCity' para crear una red paneuropea.

El emprendimiento en América Latina se aprecia de la siguiente forma: "Muchas empresas y poca innovación". Las empresas latinoamericanas introducen productos nuevos a un ritmo menor que las empresas de otras regiones en desarrollo. Países como Ecuador, Jamaica, México y Venezuela que introducen o desarrollan productos nuevos a una evolución que es menos de la mitad que en países como Tailandia o Macedonia. Según el Banco Mundial (2018) excepcionalmente Brasil invierte el uno por ciento de su PIB en Investigación y Desarrollo, en promedio la región invierte mucho menos, es decir, un tercio el nivel de China y un cuarto el nivel de los países de elevados ingresos. Sin embargo, el gobierno lleva a cabo la mayor parte de la inversión latinoamericana en este campo.

Una recién investigación evidenció que las empresas que emplean cien personas o menos, no emplean los sistemas más innovadores y actualizados de gestión de talento basado en el desempeño. En América Latina tienen un gran volumen de empresas familiares peor gestionadas que duplica a la de Estados Unidos (Redtransfernoticias, 2018)

6. Contrato de aprendizaje: Este tipo de contrato es una manera especial de vinculación a una empresa y está 
enfocada a la formación de practicantes, donde este recibe herramientas académicas y teóricas en una entidad autorizada por una universidad o instituto, con el soporte de una empresa patrocinadora que suministra los medios para que el practicante adquiera formación profesional metódica en el oficio. El fin de este tipo de contrato es el aprendizaje y que el practicante pueda acceder al mundo laboral, la remuneración es denominada "auxilio" de sostenimiento y depende completamente de un convenio entre ambas partes, donde el estudiante no tiene prestaciones sociales. El valor de la remuneración depende de si el alumno en prácticas es universitario o no, de ser universitario tiene derecho a un salario que debe ser superior o igual al mínimo fijado por Ley y si el practicante no es universitario tendrá como base de pago un salario por debajo del mínimo (David Rueda, G., 2016).

En España tiene un sistema similar donde hay una diferenciación contractual, entre aquellas personas que tienen un título, ya sea certificado de profesionalidad, ciclo de grado medio o superior, grado, máster o doctorado y aquellas personas que son analfabetas. Por tanto, las personas que poseen un título se formalizará legalmente en un contrato en prácticas con una duración determinada. En este caso el estudiante debe estar dado de alta en la Seguridad Social. Lógicamente su remuneración es inferior a la de otra persona que ocupa el mismo puesto, pero la diferencia no supera el $25 \%$. Es una iniciativa que trata de favorecer el acceso del alumnado al mercado de trabajo y pueda obtener experiencias que en tantas ofertas de trabajo se exige.

Por otro lado, se posee una gran cantidad de personas que no tienen formación reglada de ningún tipo ¿Qué trata de potencia la UE? Que estas personas a través de un contrato de formación y aprendizaje puedan acceder a una parte tanto teórica como práctica y la finalización de este contrato temporal, permitiría obtener la adquisición de una titulación teórica.

Asimismo, estas iniciativas permiten una protección del alumnado que está en proceso de desarrollo de sus habilidades y competencias y le permite el networking, tan importante hoy en día para el acceso a un empleo. Además, se debe tener en consideración los incentivos en las cuotas de la Seguridad Social tanto por la celebración del contrato de trabajo ya sea en prácticas o de formación y de aprendizaje. Asimismo, si estos contratos son convertidos en indefinidos también existen bonificaciones a las cuotas de la seguridad social. Desde la UE se persiguen tener resultados con unos incentivos directos, claros, precisos y adecuados al contexto de España.

Contrato de Obra o labor: Este contrato es por una labor específica y termina en el momento que la obra o servicio finalice. Este tipo de vinculación es característica de trabajos de construcción y de universidades y colegios con profesores de cátedra, que cumplen su labor una vez haya terminado el periodo académico. Este contrato es igual en términos de beneficios y descuentos a los contratos indefinidos y definidos, por ser un contrato laboral.

Es importante tener en cuenta que si las empresas contratan personal de manera irregular se exponen a sanciones o multas que no solo es un duro golpe a las finanzas de la empresa sino a su reputación (Rojas, A., 2008). 
Relaciones laborales ¿Una realidad estructural, coyuntural o un perjuicio instaurado a nivel mundial?

Bayón Pérez, Jessica y Arenas Falótico, Andrés Jerónimo

\subsubsection{Argentina}

En este país el régimen constitucional de Contrato de Trabajo estipula, como regla general, que las relaciones laborales son permanentes.

Sin embargo, existen los contratos a tiempo determinado, los que no pueden tener una duración superior a los 5 años. Para que estos contratos sean válidos deben quedar por escrito las condiciones y la duración del contrato. Asimismo, el tipo de tarea o actividad deben justificar su uso. La sucesiva celebración de estos contratos, que supere los requerimientos de la tarea o actividad, lo convierte en uno por tiempo indeterminado.

Desde un punto de vista europeo, pueden existir sectores económicos donde abunda la temporalidad, por ejemplo, en la hostelería. Sin embargo, de forma genérica los contratos temporales deben estar especificada la causa de por qué se está celebrando de forma temporal. Esto impide que haya una secesión irregular de los mismos. Si comparamos Colombia y Argentina, prima mayormente la temporalidad con políticas inactivas que incentiven mejores empleos y estables (Isaza, J. G., 2018).

El despido injustificado antes de la finalización del contrato genera para el trabajador el derecho a percibir, además de la indemnización por la finalización del contrato en estas condiciones, una cantidad simbólica adicional por los daños y perjuicios ocasionados en tales circunstancias. Los tres primeros meses del contrato a tiempo indefinido constituyen el período de prueba, el cual no puede ser utilizado por el empleador más de una vez con el mismo empleado.

Cabe la posibilidad de celebrar contratos de temporada o eventuales. El de temporada, responde a la estacionalidad de las actividades realizadas en la empresa mientras que el eventual se origina en demandas extraordinarias de empleo frente a circunstancias específicas que experimenta la firma. En ambos casos los trabajadores gozan de los mismos derechos que los trabajadores permanentes, siempre que reúnan los requisitos estipulados para su acceso.

Por otro lado, el contrato puede ser a tiempo completo o parcial. Este último queda definido como aquel donde el trabajador presta sus servicios por un total de horas al día o a la semana inferior a las dos terceras partes de la jornada habitual de la actividad en la que se desarrolla. Este tipo de empleo puede realizarse bajo un contrato indefinido o temporal. No es posible realizar horas extras a la vez que cualquier incumplimiento del límite máximo de la jornada a tiempo parcial obliga al empleador a abonar el salario mensual correspondiente a la jornada completa, además de las consecuencias que se deriven de dicho incumplimiento.

La remuneración en los contratos tiempo parcial es como mínimo proporcional a la que le corresponde por convenio a un trabajador de su misma categoría a tiempo completo o a la que fija el salario mínimo. Si la jornada supera los dos tercios de la jornada completa el empleador debe abonar la remuneración correspondiente a un trabajador tiempo completo. Las cotizaciones a la seguridad social se realizan en proporción a la remuneración del trabajador y deben ser unificadas en caso de pluriempleo.

Las negociaciones colectivas deben determinar el porcentaje máximo de trabajadores a tiempo parcial en el establecimiento. Asimismo, pueden establecer la prioridad para que éstos 
ocupen las vacantes a tiempo completo que se generen en el mismo.

\subsubsection{Brasil}

La norma establecida de Contrato de Trabajo de Brasil también admite la celebración de contratos a tiempo determinado o indefinido.

El contrato por tiempo determinado tiene una duración máxima de dos años y no es prorrogable.

El contrato de tiempo indeterminado permite a los trabajadores temporales que gozan de los mismos derechos que los que están bajo contrato a tiempo indefinido, salvo la indemnización por despido si la relación laboral finaliza en el tiempo contraído (UN. CEPAL-OIT, 2018).

Todos los contratos tanto a tiempo determinado como indeterminado pueden ser de jornada completa o reducida. La jornada ordinaria, tiene un máximo de 8 horas diarias (con un máximo de 2 horas extras diarias), mientras que la reducida es inferior o igual a 25 horas a la semana. Las horas extras están prohibidas en este segundo caso a la vez que la jornada diaria no puede superar las 8 horas, al igual que en el contrato a tiempo completo. El salario es proporcional al obtenido por un trabajador que desarrolle las mismas labores a tiempo completo (UN. CEPALOIT, 2018).

\subsubsection{Chile}

El Código de trabajo chileno ${ }^{3}$ establece que el contrato laboral debe ser por escrito y firmado por ambas partes. Estos contratos pueden ser de naturaleza indeterminada $\mathrm{o}$ a plazo fijo. La duración no puede exceder el año (salvo en el caso de los gerentes, profesionales o técnicos la duración máxima no puede ser superior a los dos años) (Torres, M., 2018).

Cuando los trabajadores

que prestan servicios de manera discontinua, a través de más de dos contratos a plazo, durante 12 meses o más en un periodo de 15 meses, serán considerados trabajadores a tiempo indefinido. Lo mismo sucede cuando el trabajador continúa prestando servicios una vez finalizado el plazo del contrato o en el caso de una segunda prórroga. En ambos casos el contrato a plazo fijo se convierte en tiempo indefinido (Torres, M., 2018).

La duración de la jornada ordinaria de trabajo no puede ser superior a 45 horas semanales, con algunas excepciones. Sin embargo, también es posible celebrar contratos de trabajo con jornada a tiempo parcial, los cuales, al igual que en Argentina, son aquellos en los que se ha pactado una duración de la jornada no superior a dos tercios de la ordinaria. En estos casos el salario mensual no puede ser inferior al salario mínimo vigente proporcional conforme a las horas trabajadas. Estos trabajadores gozan de los mismos derechos que aquellos con contrato a tiempo completo. (Torres, M., 2018).

El Código permite la subcontratación laboral y el trabajo en empresas de servicios transitorios,

3 D.F.L. Núm. 1.- Santiago, 31 de julio de 2002. 
Relaciones laborales ¿Una realidad estructural, coyuntural o un perjuicio instaurado a nivel mundial?

Bayón Pérez, Jessica y Arenas Falótico, Andrés Jerónimo

conocidos en España como las Empresas de Trabajo Temporal e igualmente la subcontratación laboral.

\subsubsection{Ecuador}

El código de trabajo ecuatoriano ${ }^{4}$ establece que el contrato de trabajo puede ser expreso (verbal o escrito) o tácito. Como en otros países sino esta por escrito, difícilmente tiene carga de la prueba sobre todo para cuestiones de condiciones laborales, modificaciones sustanciales del contrato de trabajo, etc.

En aquellos casos donde no existe un contrato escrito, se considera tácita toda relación laboral entre empleador y empleado. Éste adquiere los mismos derechos en cualquiera de estas circunstancias.

Sin embargo, en algunos casos, es obligatoria la celebración de un contrato escrito. En particular, ello debe ser así cuando el trabajo requiere conocimiento técnico, profesional o de un arte; cuando es un contrato por obra donde el valor de la mano de obra excede de cinco salarios mínimos; cuando se trata de un contrato a destajo o por tarea con más de un año de duración; o en los casos de contratos a prueba, eventuales o de temporada.

Según el Ministerio de Trabajo de Ecuador (2018) los contratos pueden ser por tiempo fijo, indeterminado, por temporada, eventual, ocasional, por obra, por tarea, a prueba (con duración máxima de 3 meses y no prorrogable entre las partes) o a destajo. Este último, existe en España sobre todo en la campaña de la aceituna donde los trabajadores obtienen ingresos diferentes, dependiendo de los kilos de aceitunas cogidas. En Ecuador se establece, como regla general, una duración mínima de un año, para los contratos a tiempo fijo o indeterminado.

Cabe resaltar que, en los contratos eventuales, la retribución percibida será un 35 por ciento superior al valor por hora del salario básico del sector al que corresponde el empleado.

Está prohibida la tercerización, la intermediación laboral, y la contratación laboral por horas, entendiendo que estas formas contractuales precarizan el empleo, vulneran el principio de estabilidad laboral, impiden la organización sindical y desconocen los convenios internacionales (Maldonado Mera, Betzabé del Rosario; Buenaño Cabrera, José Javier \& Benavides Espinosa, Karla Viviana, 2018).

La jornada parcial es aquella cuya duración es inferior a la de la jornada normal de 8 horas diarias no pudiendo superar las 40 horas semanales. En algunos casos particulares se permite otra duración de la jornada laboral. El contrato de trabajo a tiempo parcial puede estipularse por tiempo indefinido o por duración determinada, siempre por escrito 5 .

Se establece que la remuneración se determinará, considerando la proporcionalidad en relación a la jornada completa, que no podrá ser inferior a los mínimos vitales generales o sectoriales. De esta manera también se abonarán los otros beneficios establecidos en

\footnotetext{
$4 \quad$ Ibidem

5 Ley Orgánica para la promoción del trabajo juvenil, regulación excepcional de la jornada de trabajo, cesantía y seguro en el empleo.
} 
su ordenamiento jurídico a excepción de aquellos que por su naturaleza no pueden dividirse, que se pagarán íntegramente. Estos trabajadores tendrán derecho a todos los beneficios laborales, entre otros, la cobertura del seguro social obligatorio.

No obstante, el mandato permite la celebración de contratos con empresas autorizadas como prestadores de actividades complementarias por el Ministerio de Trabajo y Empleo "cuyo objeto exclusivo sea la realización de actividades complementarias de: vigilancia, seguridad, alimentación, mensajería y limpieza, ajenas a las labores propias o habituales del proceso productivo de la usuaria". Los trabajadores gozarán de todos los derechos laborales. Estos contratos obligatoriamente deben ser realizados por escrito y certificados frente al citado Ministerio. (Ministerio de Trabajo de Ecuador, 2018).

\subsubsection{Perú}

La Ley General del Trabajo en Perú establece que el contrato estándar es por tiempo indeterminado, salvo que se especifique lo contrario (Dossantos, Rebbeca., 2017).

Los contratos celebrados pueden ser escritos o verbales, si bien en algunos casos deben obligatoriamente realizarse por escrito. Pueden celebrarse contratos a tiempo determinado en casos en que lo exija la naturaleza temporal de la tarea o actividad, es decir, al igual que en España se debe justificar debidamente la temporalidad. El contrato escrito debe contener las causas de esta contratación y por qué de su categoría determinada, sus características y su duración. Sin embargo, las causas pueden ser muy diversas. La primera de ella, es por las necesidades de mercado, donde los aumentos de demanda coyunturales no pueden ser cubiertos por el personal permanente. La duración máxima de este tipo de contrato es de un año. También se puede contratar personal por inicio o incremento de la actividad (que correspondería al contrato eventual por circunstancias de la producción española). Por su parte, el contrato ocasional se celebra para obtener personal para actividades transitorias y diferentes a la actividad principal o habitual de la empresa. Su duración máxima es de seis meses.

El contrato de suplencia (en España de interinidad) permite sustituir a un trabajador permanente que se no encuentra trabajando por un tiempo determinado siendo su causa justificada, por lo que su puesto queda reservado para el titular y, por ende, la contratación tendrá la duración de dicha licencia. El contrato de interinidad en España es muy común no solo para las empresas privadas sino para las Administraciones Públicas. En el contrato ha de expresarse explícitamente la persona a la que sustituye, el tiempo si se puede definir y la causa de sustitución. Se da en casos como bajas por maternidad, bajas por incapacidad temporal, etc. Cuando el titular se reincorpore, el contrato quedará finalizado (Medina, J., Mendoza, S., Morales, G., \& Vera, P., 2018).

En los contratos por obra o servicio su duración determinada dependerá del tiempo necesario para su finalización al igual que en España. Se permite la renovación de este tipo de contrato hasta tanto se dé por finalizada la obra o el servicio. A diferencia de este tipo de contrato español tiene una duración máxima de tres años ampliable a uno más si es permitido por 
Relaciones laborales ¿Una realidad estructural, coyuntural o un perjuicio instaurado a nivel mundial?

Bayón Pérez, Jessica y Arenas Falótico, Andrés Jerónimo

convenio colectivo. Pueden firmarse en Perú contratos temporales por las necesidades de mercado y ocasionales con el mismo empleador, pero entre ambos no pueden superar los dieciocho meses. Los contratos de un tiempo periódico o llamados de temporada, están asociados a la periodicidad en su repetición y son considerados de tiempo indeterminado.

Cabe indicar por lo que aquí se refiere al hecho de que en los contratos a tiempo determinado existe el período de prueba estipulado por la Ley laboral. Éste es de tres meses, salvo en el caso de los trabajadores de dirección que puede extenderse a seis meses.

Al igual que en otros muchos países, este tipo de contrato puede convertirse tácitamente en indeterminado si: El trabajador continua trabajando tras su finalización o existen sucesivas prórrogas establecidas (concatenación de contratos de trabajo temporales); $\mathrm{Si}$ el trabajador continua la relación laboral una vez finalizada la obra o servicio, si el titular no se reincorpora de su licencia y el trabajador continua trabajando, o cuando el contrato no ha sido celebrado por escrito o lo ha sido bajo fraude de ley. Los trabajadores contratados a tiempo determinado tienen los mismos derechos y beneficios que aquellos que están contratados de forma indeterminada (Medina, J., Mendoza, S., Morales, G., \& Vera, P., 2018).

El contrato de trabajo a tiempo parcial es aquel que demanda una jornada de menos de 4 horas diarias o menos de 24 horas semanales. Este contrato puede ser por tiempo determinado 0 indefinido. Los trabajadores tiempo parcial disfrutan de los mismos derechos que los de jornada completa salvo en el caso de aquellos para cuya percepción se exija trabajar un mínimo de cuatro horas diarias o de veinticuatro horas semanales. Asimismo, el salario mínimo en estos contratos es una proporción del estipulado para el contrato a tiempo completo en función de las horas trabajadas.

\section{2.- Formas de contratación:}

\section{2.a) Empleo a tiempo parcial}

El trabajo a tiempo parcial ha venido creciendo sistemáticamente en un conjunto importante de países. Por un lado, el subempleo podría ser voluntario por parte del empleado quien desea trabajar menos horas y el empleador lo acepta bien porque este esquema resulta compatible con las necesidades de su empresa o bien como una estrategia para retener al trabajador. En este sentido, estos arreglos de menor cantidad de horas podrían ser preferibles para cierto conjunto de trabajadores que no desean o no pueden dedicarle una jornada completa al trabajo para el mercado. Las mujeres y los jóvenes, que poseen otras responsabilidades extralaborales como formación, cuidados de personas dependientes con un grado de consanguinidad de primer y segundo grado, cuidado de hijos, etc. pueden requerir de este tipo de puestos para permanecer en activo y evitar lagunas laborales. Ello mismo puede generar abuso por parte de los empleadores al ofrecerles a estos grupos de trabajadores exclusiva o mayoritariamente este tipo 
de ocupaciones ${ }^{6}$.

Los empleadores, asimismo, pueden utilizar este tipo de puestos para lograr mayor flexibilidad en el manejo del personal frente al ciclo económico o para reducir costes salariales. Al mismo tiempo, estos tipos de puestos pueden estar asociados a condiciones laborales menos favorables, salarios precarios, impedimentos para lograr la promoción y dificultades para acceder a la cobertura de la seguridad social.

Adicionalmente, los trabajadores con esta jornada suelen recibir menor capacitación en el puesto debido a que los empleadores consideran que éstos contribuyen en menor cuantía a la dinámica y desarrollo corporativo o que están menos interesados en desarrollarles una carrera profesional activa. Debemos nombrar la existencia de una "trampa del empleo part-time", donde la falta de acceso a la capacitación específica atenta contra la posibilidad de transitar hacia una posición a tiempo completo y de hacer carrera dentro de la empresa como la protección eficaz y eficiente de su salud laboral. En este sentido, un aspecto importante es que, si este tipo de puestos es transitorio hasta que se accede a un puesto de jornada completa o, sí, por el contrario, constituye una situación permanente como en la mayoría de los casos ${ }^{7}$

En algunos casos, el empleo a tiempo parcial se asocia a la posibilidad de tener horarios de trabajo variables o flexibles. Cuando este esquema es determinado por el trabajador ello puede facilitarle la compatibilización del trabajo con actividades no laborales como la conciliación con la vida familiar. Sin embargo, cuando ello es decidido unilateralmente por el empleador puede generar una situación de imprevisibilidad que dificulte la compatibilización con otras tareas y reduzca o elimine la posibilidad de contar con otro empleo a tiempo parcial. Asimismo, algunos estudios encuentran que el trabajo en horas no habituales (nocturno o fines de semana).

Por otro lado, se argumenta por algunos autores Bollain, Julen y Raventòs, Daniel (2018) que estos puestos pueden conllevar mayores costes administrativos asociados al manejo de un número mayor de trabajadores. Ello podría implicar menores salarios netos como una forma de compensar estos mayores costes. A su vez, éstos podrían ser crecientes con el nivel de calificación. Si ello es así, podría implicar, por un lado, que estos puestos se concentren entre los asalariados de menor nivel educativo $\mathrm{y}$, por otro lado, que la penalidad salarial sea más elevada entre los trabajadores part-time más cualificados.

Así pues, en términos agregados, este fenómeno puede ser causa de segmentación en el mercado de trabajo donde, ya que las condiciones laborales de este tipo de puestos difieran significativamente de las de un puesto full-time $\mathrm{y}$, por otro, donde exista una escasa movilidad desde un empleo a tiempo parcial a otro a tiempo completo. Al mismo tiempo, podría generarse una situación de segregación ocupacional si estos puestos se correlacionan con ciertos atributos personales de los 
Relaciones laborales ¿Una realidad estructural, coyuntural o un perjuicio instaurado a nivel mundial?

Bayón Pérez, Jessica y Arenas Falótico, Andrés Jerónimo

trabajadores (como, por ejemplo, el género, la edad, el nivel educativo...).

En este sentido, las normas laborales vigentes en cada país resultan de especial relevancia, ya que pueden reducir o potenciar las vulnerabilidades a las que pueden estar expuestos estos trabajadores. Por ejemplo, ello será diferente si la legislación contempla o no el principio de proporcionalidad en cuanto a la determinación salarial y a los beneficios no salariales respecto de los trabajadores similares a tiempo completo. A veces los empleos a medio tiempo o part-time quedan excluidos de los beneficios de la seguridad social. Esto se debe a los mínimos impuestos abonados en términos de horas trabajadas o de contribuciones para acceder a los mismos.

\section{2. b) El empleo temporal}

La existencia de contratos con una duración determinada podría deberse entre otros: A la necesidad de los empleadores o empresarias de contar con un "período de prueba" donde evaluar de forma menos costosa que bajo un contrato indefinido si la relación entre las funciones y labores del puesto y las aptitudes, actitudes, habilidades y competencias del trabajador es satisfactoria. Si la correlación anterior es negativa, el empresario puede tomar la decisión de no renovar el contrato, sin tener que enfrentar los costes de despido. Asimismo, este tipo de ocupaciones podrían ser un puente hacia una posición indefinida ("stepping stone").

Por su naturaleza, este tipo de empleo, los empleados con una relación laboral de carácter temporal son más proclives que los indefinidos a experimentar una inestabilidad ocupacional y profesional, a sufrir una mayor precariedad en el empleo, ya que una vez finaliza el contrato, la parte empresarial puede decidir no continuar con dicha relación laboral. Al mismo tiempo, debido a la mayor facilidad para finalizar con esta relación formal de carácter laboral, el efecto del ciclo económico suele ser mayor en estas ocupaciones.

En una situación totalmente opuesta, los trabajadores acogidos con una relación laboral de carácter indefinida, además de proporcionarles una mayor estabilidad, reciben, en general, mayores oportunidades de promoción en el puesto, desarrollo personal y profesional y mayores salarios o condiciones laborales altamente atractivas de acuerdo con la categoría laboral y grupo profesional. Igualmente, este tipo de personal cuenta con una mayor protección en caso de despidos, bajas, riesgos laborales, etc ${ }^{8}$

Sin embargo, se argumenta que los trabajadores con una relación laboral de carácter temporal pueden recibir un premio salarial (en vez de una penalidad) de este modo, se pretende compensar la falta de otros beneficios y de condiciones laborales más convenientes y favorables.

Se hace referencia aquí a lo que Adam Smith (1776) refería como "diferencias compensadoras", por lo cual, el salario de un determinado puesto reflejaría las ventajas y desventajas que el mismo ofrece. En este sentido, la remuneración horaria es superior por la 
"desventaja" asociada a, por ejemplo, la menor estabilidad de estas ocupaciones $y$, por ende, la incertidumbre respecto de los salarios futuros.

Al mismo tiempo, el hecho de permanecer un corto periodo de tiempo en el puesto de trabajo, provoca mayores dificultades o barreras para recibir entrenamiento en la firma. Por un lado, se argumenta que en este contexto los trabajadores pueden ser menos proclives a capacitarse si consideran que las probabilidades de conversión de su contrato temporal por uno indefinido son bajas y escasas y que, por ende, la duración en la empresa será reducida. Esto no solo afecta a nivel económico, pues los estudiosos de recursos humanos pueden apreciar una mayor cantidad de consecuencias negativas en la organización. Si varias personas dentro de la empresa tienen una relación de trabajo de corta duración y conocen su efímera estancia tiene consecuencias en la actitud, productividad, clima laboral, mayor índice de absentismo, rotación de personal, bajas por incapacidad, etc. De esta forma los costes económicos y de reputación interna y externa se ven mermadas. Si la imagen de las personas que tiene a nivel interno, puede apreciar valores, misión, visión y actuaciones que no están en consonancia con los mismos pueden decidir extinguir unilateralmente la relación laboral para generar productividad con las inversiones formativas de la anterior organización. Por otro lado, desde el puesto de vista del empleador, éste estará menos interesado en capacitar a un trabajador que permanecerá un periodo de tiempo reducido en la empresa por lo que no podrá disfrutar completamente los incrementos de productividad asociados al aumento en el capital humano específico. La combinación de menores posibilidades de recibir formación constante y actualizada y mayor rotación ocupacional atentan, a su vez, contra la probabilidad de que el trabajador pueda realizar trayectorias laborales ascendentes ${ }^{9}$.

Vinculado a lo anterior, los empleos temporales también podrían implicar menores niveles de productividad laboral como se ha comentado previamente. Ello podría estar asociado al hecho de que los trabajadores realizarán un menor esfuerzo debido a las escasas expectativas de obtener un puesto estable en la empresa. Esta inseguridad laboral que perciben estos trabajadores pueden provocar problemas de salud.

Por último, al igual que en el caso del empleo a tiempo parcial, la legislación laboral puede acrecentar o disminuir la brecha en las condiciones laborales entre trabajadores temporales y permanentes. Ello depende de la medida de inclusión o exclusión de las normas protectoras y de los derechos laborales que disfruta un puesto con contrato indefinido. Asimismo, la estabilidad macroeconómica, la demanda de empleo y la diferencia de costes entre un trabajador indefinido y temporal serán factores que afectarán la posibilidad de que un puesto transitorio pueda convertirse efectivamente en uno indefinido.

\section{2.c) Empleo triangular}

Otras de las formas no comunes 
Relaciones laborales ¿Una realidad estructural, coyuntural o un perjuicio instaurado a nivel mundial?

Bayón Pérez, Jessica y Arenas Falótico, Andrés Jerónimo

de generar empleo es la triangulación laboral, es decir, la relación entre el empleador, empresa usuaria y el trabajador. Existen situaciones asociadas a la estacionalidad del empleo o a fluctuaciones de corto plazo donde se puede esperar que se recurra a este tipo de empleo. Sin embargo, la preocupación aparece generalmente cuando los trabajadores subcontratados o temporales de agencia, comienzan a ocupar puestos esenciales dentro de la empresa, pero en condiciones laborales inferiores a las de los trabajadores indefinidos contratados de forma directa. En este sentido, la relación triangular entre el asalariado, la agencia de empleo y la empresa que finalmente hace uso de la mano de obra, puede resultar propicia para el incumplimiento de la normativa laboral con impactos negativos sobre las condiciones en las que se desarrollan estos profesionales.

Ello implica, por ejemplo, que éstos puedan recibir salarios inferiores, menos derechos y un menor acceso a los beneficios de la seguridad social que los que perciben los trabajadores de planta con similares características y realizando las mismas tareas. Ello se refuerza a partir de las barreras que este tipo de trabajadores experimentan en materia de representación sindical. Se concluye que no siempre está garantizado el derecho a afiliarse a un sindicado $y$, al mismo tiempo, a estar amparado en una negociación colectiva con la empresa usuaria. De hecho, ésta puede ser una de las razones por las cuales un empleador recurre a la tercerización laboral.

En España se producen a menudo estas relaciones triangulares ¿Por qué? De acuerdo con Jaime, María del Carmen (2018) El 95\% de las empresas en España son pequeñas o medianas.
Las empresas que están implantadas a nivel nacional prefieren celebrar un contrato con otra empresa que se haga cargo de todos los costes de selección de personal, altas, bajas, modificaciones de contratos, despidos, indemnizaciones, finiquitos, prevención de riesgos laborales, material para trabajar, etc. De esta forma, se externalizan todas las labores de dirección y administración de personal y laboral, y así, obtienen menos costes a cambio de una contraprestación que deben aportar a la empresa encargada de todas las labores.

Un estudio reciente realizado de manera conjunta por la Confederación Sindical de Trabajadores y Trabajadoras de las Américas y la Confederación Sindical Internacional (año 2013) sobre las Agencias de Trabajo Transitorio (ATT) se aportan algunos datos relevantes, no solo para este país sino, también, para Argentina, Brasil y Perú, entre otros casos no considerados aquí tales como Colombia, México, Panamá y Uruguay. Además de señalar las dificultades que esta forma de tercerización puede generar en relación con las condiciones laborales, también intenta cuantificar la importancia relativa que este tipo de contratación tiene en el empleo asalariado en la región.

Indican que en casi todos estos países están presentes tres empresas transnacionales de gran relevancia: Adecco, Randstad y Manpower. Este tipo de contratación se extiende por una amplia gama de sectores económicos. Si bien la industria y el comercio parecen ser los más importantes, también en los servicios, transporte, construcción y actividades agrícolas se utiliza mano de obra proveniente de agencias de empleo. Colombia es el país que mayor uso hace de este tipo de contratación (8.7\% de la ocupación asalariada), le 
sigue Perú (2.5\%), Brasil y Chile (1.8\%) Uruguay $(1.3 \%)$ y Argentina y México (alrededor de $0.5 \%$ ). Sobre los jóvenes, las mujeres y los trabajadores de menor nivel educativo recaen mayoritariamente este tipo de intermediación laboral.

\section{3.- Apreciaciones contractuales en América Latina}

A diferencia de lo que sucede en el mundo desarrollado, existen pocos estudios sobre la incidencia, evolución y características de formas no comunes de empleo en América Latina. Refiriéndonos a los siguientes:

Un estudio reciente citado por Pagés-Serra, Carmen (2018) evalúan en qué medida los empleos temporales (incluyendo contratos a tiempo determinado y el empleo a través de agencias) son fuente de segmentación y desigualdad salarial. El estudio incluye los países de la OCDE y algunos de América Latina. De acuerdo con este estudio, dentro de las formas no estándar de empleo, el empleo temporario ha sido uno de los que más ha crecido durante los últimos años. Encuentran una correlación positiva entre mayor prevalencia de contratos a plazo fijo y desigualdad salarial, aun controlando por otros determinantes de ésta. Asimismo, se puede observar que en Chile una proporción importante de empleo temporal se concentra en la triangulación laboral, donde se incluye el contrato por agencia y la subcontratación.

En dichos países, al igual que en otros, los trabajadores temporales reciben menor capacitación a cargo de la empresa que los trabajadores permanentes.

De todos los autores y fuentes contrastadas, destaca la aparición de nuevas formas no estándar de trabajo caracterizadas por condiciones precarias de empleo. Entre ellas se observa la temporalidad laboral, la subcontratación y el trabajo a tiempo parcial. Esta circunstancia se concentra específicamente en el empleo part-time en Chile. El ordenamiento jurídico chileno establece que las empresas con más de diecinueve empleados deben proveer salas con cunas donde dejar a sus hijos menores de dos años en el horario laboral puede ser un potencial desincentivo para el uso de contratos parttime, dado que este tipo de trabajadores cuentan igual que aquellos a tiempo completo para llegar a este umbral, lo que encarece la contratación de trabajadores de jornada parcial, mayormente mujeres. Asimismo, encuentra que estos puestos se caracterizan por una mayor inestabilidad, por falta de contrato o de contrato a tiempo indefinido, por un menor acceso al seguro de desempleo y por mayor incidencia de la pobreza, en comparación con los empleos a tiempo completo.

Es relevante analizar la calidad del empleo en varios países de América Latina. La estabilidad de la relación laboral es percibida como uno de los componentes de la calidad de las ocupaciones. Existe una fuerte discrepancia entre Argentina y Costa Rica, por un lado, (donde alrededor del $70 \%$ de los asalariados están en una relación permanente) y Ecuador donde la mitad de los puestos son temporales. En este país, analiza la situación laboral en comparación con Bolivia ${ }^{10}$. Encuentra en ambos casos una muy elevada inestabilidad laboral asociada, por un lado, a la falta de contratación laboral y, por otro, a la prevalencia de contratos temporales. Estos ámbitos y otras 
Relaciones laborales ¿Una realidad estructural, coyuntural o un perjuicio instaurado a nivel mundial?

Bayón Pérez, Jessica y Arenas Falótico, Andrés Jerónimo

dimensiones hacen que la calidad de empleo en Perú durante la última década y el uso masivo de contratos a plazo fijo o sin contrato, siendo éste uno de los países con mayor proporción de este tipo de modalidades de contratación en la región.

Finalmente, se procede a una evaluación de los determinantes del uso de contratos temporales en 135 países en vías en desarrollo. Para ello, emplean la World Bank Enterprises Survey ${ }^{11}$ que recoge información sobre este tipo de contratos entre los trabajadores a tiempo completo en empresas formales de la industria o servicios con cinco o más ocupados. Ellas encuentran que, como en los países desarrollados, la necesidad de flexibilidad externa es una de las razones más importantes para la utilización de este tipo de contratos, conjuntamente con la posibilidad de reducir costes laborales. A su vez, encuentran que algunas regulaciones laborales específicas pueden limitar su uso. Por el contrario, el ciclo económico no parece tener un impacto significativo sobre la prevalencia de este tipo de empleo, si bien el nivel de desarrollo del país sí está negativamente correlacionado con la temporalidad laboral.

La informalidad laboral continúa siendo una especial característica distintiva de América Latina.

América Latina en la última década, ha experimentado un proceso de mejora significativa del mercado de trabajo. Ello se expresa fundamentalmente a través de una reducción del desempleo, creación de nuevos puestos de trabajo, incremento del salario medio y formalización de los empleos.

No obstante, a pesar de estas mejoras, los países de la región continúan evidenciando déficits importantes en materia laboral y en la generación y distribución de ingresos. A la elevada informalidad se le suma la presencia de formas no comunes de empleo.

Se analizó la incidencia de estos fenómenos en el total del empleo asalariado y en diferentes subgrupos de trabajadores. Además, se añade a la evolución durante la última década y se evaluó en qué medida el empleo atípico o no común va acompañado de una penalización salarial y de condiciones laborales mucho más precarias. La selección de países permitió contar con un panorama exhaustivo de la región, ya que los mismos exhiben estructuras y dinámicas laborales muy disímiles entre sí.

Adquiere mayor relevancia el trabajo temporal que el empleo a tiempo parcial. Ello se debe tanto a la mayor prevalencia global del primero como a su mayor incidencia en ciertos grupos de trabajadores. Particularmente, la temporalidad afecta de forma más intensa a los asalariados informales, mujeres, jóvenes menores de 30 años y con menor nivel educativo. Al mismo tiempo, el trabajo temporario, además de implicar lógicamente una menor estabilidad laboral, conlleva una penalidad salarial significativa en todos los países bajo análisis. Ello sugiere una correlación positiva entre bajos salarios, precariedad y falta de ingresos laborales, que resulta aún más 
problemática si se tiene en cuenta la baja o nula protección frente al desempleo que estos países poseen. Todo ello afecta a los trabajadores de sectores desfavorables, lo que constituyen fuentes de desigualdad ${ }^{12}$.

Asimismo, esta penalidad parece reflejar el incumplimiento de la legislación laboral que en todos estos países establece iguales condiciones que los asalariados permanentes en la determinación salarial. Sin embargo, la escasa inspección laboral y la menor sindicalización por parte de los trabajadores con contrato fijo contribuye a obtener estos resultados.

\section{4.- Comparación mundial de la tasa de empleo, ¿Las políticas e iniciativas lanzadas han logrado su propósito? 0 ¿Han sido medidas tirita?}

Como se puede apreciar en el gráfico 1, la UE tiene una tasa de temporalidad contractual muy bajo con respecto a los demás países destacando el logro de Rumanía, Lituania, Estonia, Bulgaría, etc.

Por otro lado, países que tiene en elevado grado de temporalidad son Polonia, España, Portugal, Noruega y Turquía.

\section{Gráfico 1 \\ Comparación global de la temporalidad en el empleo}

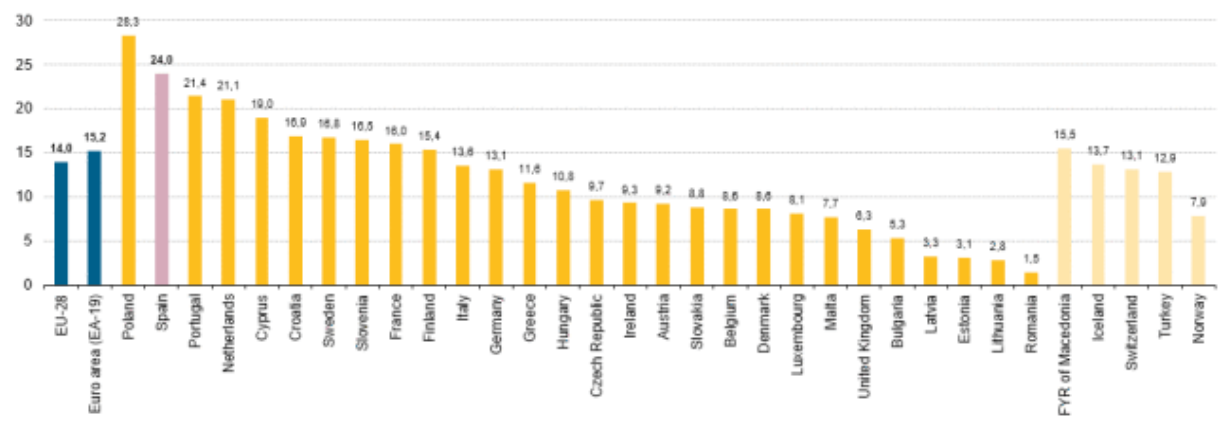

Fuente: Martín, F. J., (2017). Tasa de empleo. Eurostat.

Según EFE Sau Paulo, (2018): Un $21 \%$ de los jóvenes en Latinoamérica ni estudia ni trabaja son denominados "NiNis". Los mayores índices de los mismos se registraron en México (25 $\%)$, El Salvador (24\%), Brasil (23\%) y
Haití (19\%). Por otro lado, el $70 \%$ de los jóvenes que trabajan lo hacen en actividades informales, y entre los que están dentro del mercado formal, hay una alta temporalidad. En contraste con lo anterior, en la actualidad, los NiNis 
Relaciones laborales ¿Una realidad estructural, coyuntural o un perjuicio instaurado a nivel mundial?

Bayón Pérez, Jessica y Arenas Falótico, Andrés Jerónimo

en UE representan un $14,2 \%$ de la población de entre 15 y 29 años ${ }^{13}$. Por tanto, se puede decir que realmente las políticas públicas para mejorar el empleo joven no han tenido unos resultados notables o impactantes con todos los resultados socioeconómicos que ello conlleva.

\section{4.- Análisis contractual de ámbito laboral en el sistema comunitario}

A continuación, se va a vislumbrar las políticas sociolaborales de la Unión Europea.

\section{1.-Alemania, una gran potencia europea}

En este país, de acuerdo con las confirmaciones de Intereconomía.com (2019) el salario mínimo interprofesional alcanza en el año 2018 la cantidad de $1.645 €$, aunque los sueldos son bastante elevados, de unos 30.000 euros brutos al año para un recién licenciado y de hasta 15 euros la hora en empleos no cualificados. En España sería peculiar obtener más $22.000 €$ brutos/año de media para cualquier empleo ${ }^{14}$.

La jornada laboral oscila entre 38 y 40 horas a la semana, con jornadas diarias no superiores a las ocho horas y con descanso obligatorio de 11 horas tras un día completo y trabajo. Es obligatorio tener un día libre a la semana, aunque lo común es trabajar de lunes a viernes. En general, existe una gran flexibilidad horaria. De acuerdo con El Periódico (2018) un empleado español trabaja el $26,1 \%$ más de horas que un alemán. Asimismo, el Instituto de Estudios Económicos confirma que cualquier trabajador de Portugal, Italia, Grecia y España emplea más horas de jornada que un alemán, un danés, un holandés $\mathrm{o}$ un francés. No obstante, los europeos no son los países que concentran el mayor número de horas en todo el mundo. El país con las jornadas más amplias se genera en México. Allí, sus habitantes dedican al ámbito laboral más de 2.200 horas anuales. En otros países como Malasia, Tailandia, India y Singapur también superan la barrera de las 2.200 horas al año. Es decir, sus jornadas laborales superan las 45 horas a la semana. En China trabajan algo menos, un total de 2.007 horas (Tu Europa Unión Europea, 2019).

Las vacaciones mínimas para disfrutar en Alemania son de 24 días laborables al año, pero es común que la empresa pueda ampliar dicho plazo. Existe una mayor protección por la consideración de colectivos vulnerables como son los jóvenes o discapacitados quienes habitualmente tienen más días libres.

Todos los términos y condiciones de los contratos de índole laboral se discuten entre las partes y los convenios colectivos pueden marcar amplias diferencias de mejora en Alemania. Todos incluyen un periodo de prueba de no más de seis meses y la temporalidad siempre debe quedar eficazmente justificada. Según la Organización Internacional de Trabajo (2018) afirma que durante el año 2017 los contratos de trabajo que duraron seis meses o menos representaron más de la mitad de todos los contratos temporales en

13 Ibidem

14 Ibidem 
Bélgica, Finlandia, Italia y España mientras que en Alemania solo fueron el $15 \%$. Específicamente y acuerdo a los datos manifiesta que la temporalidad y los contratos a tiempo parcial celebrados involuntariamente hace que aumente el riesgo de pobreza entre los trabajadores.

Es interesante estudiar las políticas socioeconómicas de este país, pues cuenta con un aproximadamente un $5 \%$ de desempleo ${ }^{15}$. Por tanto, es un país ejemplar para el resto de países europeos, asiáticos o latinoamericanos.

\section{2.- Francia, un impulso a} mejorar la calidad en el empleo

En este país el salario mínimo en Francia es de 1.365 euros brutos al $\mathrm{mes}^{16}$, lo que ya de por sí son más de 400 euros más que el salario mínimo en España.

La jornada laboral es de 35 horas a la semana y todo lo que supere ese margen será considerado horas extras que deberá ser abonadas o permutadas por tiempo de descanso. Los trabajadores por cuenta ajena tienen derecho a dos días y medio de vacaciones pagadas por mes. Además, hay once días festivos al año ${ }^{17}$.

Aquí se puede distinguir cinco tipos de contratos: El indeterminado (parecido al indefinido), el determinado, el temporal, a tiempo parcial y el intermitente similar al fijo discontinuo español, pensado para trabajos de temporada. El nivel de temporalidad es escaso debido a que el Gobierno francés pretende potenciar con disminuciones en las cotizaciones sociales a las empresas que menos recurran a los contratos temporales ${ }^{18}$.

Premiar los contratos fijos $y$ penalizar los temporales. Asimismo, los contratos de muy corta duración (menos de un mes) se han multiplicado por tres en los últimos 15 años y en la actualidad representan el $70 \%$ del total. En ocho de cada diez casos, además, es la misma persona la contratada, lo que para el Gobierno francés esconde una forma de precariedad que no se justifica después de que a mediados de 2017 se flexibilizaran las condiciones de despido para las empresas.

Para hacer frente a esta idiosincrasia, los franceses apuestan por incrementar las cotizaciones laborales de las empresas que apuesten más por los contratos cortos y disminuirlas a aquellas que firmen más indefinidos, en un sistema de incentivos que en Francia se ha denominado "bonus/malus"19.

Otras de las políticas que llevan a cabo para evitar elevar la tasa de desempleo es evitar que en el paro se obtenga una retribución mayor que trabajando. Por otro lado, tratan de disminuir el máximo del subsidio. Esta medida está orientada a los desempleados con subsidios más elevados que son aquellos que cobran un máximo de $6.600 €$ al mes, hasta tres veces más que en otros países comunitarios, lo que contrasta con la "precariedad" de otros desempleados

\footnotetext{
15 Ibidem

16 Ibidem

17 Ibidem

18 Ibidem

19 Ibidem
} 
Relaciones laborales ¿Una realidad estructural, coyuntural o un perjuicio instaurado a nivel mundial?

Bayón Pérez, Jessica y Arenas Falótico, Andrés Jerónimo

peor remunerados (Hernández, G. \& Piraquive, G., 2018).

Un conjunto de medidas destinadas a mejorar la calidad de los empleos y fomentar un incremento de la tasa de ocupación, ya que Francia, es un país con aproximadamente un $10 \%$ de tasa de desempleo muy por encima de la media europea (Datosmacro.com, 2018).

\section{3.- Holanda}

El máximo de horas permitidas para trabajar es de 9 horas al día y 45 a la semana. Sin embargo, no se pueden superar las 2.080 al año, con lo que la media baja a 40 a la semana. El salario medio oscila entre los 30.000 y los 34.000 brutos al año (Sarasa, S., 2018).

Las vacaciones mínimas anuales son de 20 días, aunque la mayoría de las empresas dan cinco días más. Durante este periodo, el trabajador recibe su salario normal más una paga extra equivalente al $8 \%$ de su ganancia anual.

Sólo hay contratos indefinidos o temporal, con la diferencia respecto a España que el segundo acaba cuando expira el plazo. El empresario y el trabajador firman el contrato con las condiciones mínimas al inicio de la relación. Estos requisitos de partida van desde el salario mínimo (de 1.424 euros al mes), la jornada laboral, las vacaciones o los turnos. Todo lo demás se pacta. (Eurostat, 2018).

Por países, el detonante de la temporalidad es España con una tasa del $26,8 \%$, lo que supone que uno de cada cuatro trabajadores españoles tiene un contrato temporal. Le sigue Polonia $(26,1 \%)$, Portugal (22\%), Holanda $(21,5 \%)$ y Croacia $(20,6 \%)$. Por el contrario, las tasas más reducidas se encuentran en Rumanía (1,2\%) y Lituania $(1,7 \%)$. Por tanto, se puede apreciar una elevada tasa de temporalidad en este país con respecto a los demás (Caro, $\mathrm{C}$., 2018)

\section{4.- Reino Unido}

Es un país donde tiene ciertas particularidades que les diferencias de los demás países.

Como se puede apreciar, los mayores de 18 años pueden trabajar hasta 48 horas a la semana, mientras que entre 16 y 18 el máximo son 40 horas. El salario medio oscila entre 40.000 y 43.000 euros, de los más altos de Europa y casi doblando el salario español (Europapress, 2018).

Desde hace unos años, los británicos tienen derecho a 5,6 semanas de vacaciones por año trabajado o a 28 días $^{20}$. Todos los trabajadores, independientemente del número de horas que estén empleados, tienen derecho a tener un certificado del empleador especificado la naturaleza laboral de su relación en los dos meses siguientes a empezar a trabajar. Este certificado debe incluir los puntos básicos de cualquier puesto de trabajo: sueldo, horas, nombre del puesto, vacaciones, importe del seguro de enfermedad, planes de pensiones, despidos, huelga y procedimientos disciplinarios.

Según el periódico expansión (2018) la tasa de desempleo en Inglatera es de aproximadamente un 4\% (Oficina Nacional de Estadística, 2018).

En el siguiente gráfico 2 se puede apreciar qué lugar ocupa Reino Unido en cuanto a contratos temporales. 


\section{Gráfico 2 \\ Empleados con contratos temporales en UE}

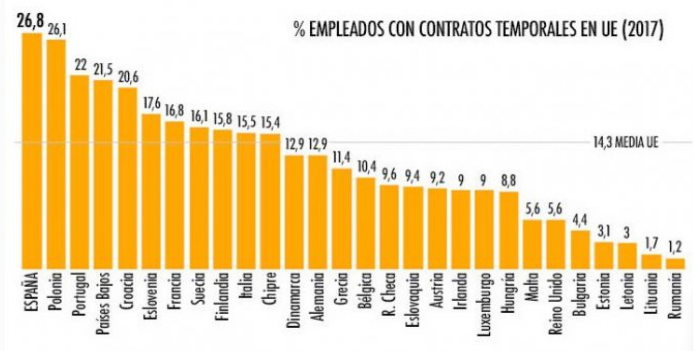

Contratos temporales en la Unión Europea en 2017 (\%) / CG

Fuente: Eurostat (2018).

Si analizamos el gráfico anterior, se puede comprobar que en el Reino Unido el nivel de contratos temporales en muy bajo. Se encuentra entre los países con menor porcentaje de temporalidad. Esto nos permite realizar una comparación con países estudiados anteriormente donde necesitan de nuevas políticas que fomenten el empleo estable con ciertas condiciones de calidad.

\section{5.- Irlanda un potencial modelo} del sistema laboral y seguridad social

El salario mínimo es el segundo más alto de Europa de 1.613,95€ y solo superado por Luxemburgo. La jornada máxima es de 48 horas semanales, por término medio, computadas en un plazo de cuatro meses, para los trabajadores en general, de seis meses para los trabajadores estacionales, y de 12 meses si está reflejado en convenio colectivo (Expansión-Datosmacro, 2019).

Se establece un mínimo de 11 horas seguidas de descanso cada 24 horas, además de 24 horas consecutivas de descanso semanal. El trabajador tiene derecho a 15 minutos de descanso si trabaja más de cuatro horas y media, y 30 minutos si trabaja más de seis horas
(Expansión-Datosmacro, 2019).

Las vacaciones dependen del tiempo trabajado en territorio irlandés: Cuatro semanas al año si se han trabajado al menos 1.365 horas, un tercio de la semana laboral por mes, en el que se trabaja al menos 117 horas y un $8 \%$ del total de horas trabajadas en un año hasta un máximo de cuatro semanas (Expansión-Datosmacro, 2019).

En Irlanda los contratos de trabajo no están tipificados, por lo que los términos y condiciones del empleo dependen del acuerdo que se establezca entre el empleador y el trabajador. Cualquiera que trabaje para un empresario por un salario regular tiene automáticamente un contrato de trabajo, sea o no escrito. Esta norma que no se aplica a las personas que hayan trabajado por menos de un mes.

\section{6.-España un país con múltiples carencias en sus políticas}

Salario mínimo interprofesional $900 €$ al mes, con 14 pagas, por lo que el salario anual será de $12.600 €$. Por 
Relaciones laborales ¿Una realidad estructural, coyuntural o un perjuicio instaurado a nivel mundial?

Bayón Pérez, Jessica y Arenas Falótico, Andrés Jerónimo

lo que la legislación laboral española indica un mínimo de 30 euros por día. Previa a los demás análisis realizados con anterioridad, se puede comprobar que España está a la cola de Europa en muchos aspectos y definitivamente las políticas sociolaborales no están dando los resultados predeterminados ${ }^{21}$. La jornada laboral de 40 horas semanales a razón de 8 horas día.

El contrato de trabajo se debe formalizar por escrito. Actualmente solo se permite el contrato verbal de duración inferior a 4 semanas en la categoría de eventual por circunstancias de la producción. Todas las demás variantes serán por escrito.

La legislación en el ámbito laboral es en principio parecida a la prevaleciente en otros países europeos, si bien existen previsiones específicas en materia de indemnización con ocasión de las jubilaciones. En cualquier caso, toda la normativa se mantiene sujeta a cambios como consecuencia de la situación financiera actual.

Desde un punto de vista críticoanalítico, España ha sido un país retocado tras la reforma del año 2012 donde se adoptaron una serie de políticas para incentivar el autoempleo como forma de disminución de la tasa de desempleo; Potenciar el empleo juvenil con diferentes modalidades de contrato como el contrato en prácticas y de formación y aprendizaje, ambos de duración determinada; En todas las políticas públicas se incentiva de forma enmascarada la flexibilidad laboral, ya que, se ha producido una erosión en los derechos de los trabajadores para mantener la supervivencia de múltiples empresas españolas; Es el país europeo con mayor tasa de temporalidad y la transformación de contratos indefinidos no llega al 9\%. Se han adoptado una serie de medidas que han sido implementadas con anterioridad y no han dado los resultados esperados, ¿por qué ahora sí qué ahora sí sería el momento de culminarlos? Es importante aprender del pasado para no cometer los mismos errores y plasmar una creativa y efectiva política que proteja, represente y logre el bien común.

\section{5.- ¿En qué deben instruirse los latinoamericanos de los europeos? Y, ¿los europeos de los latinoamericanos?}

5.1.- Aspectos técnicos y políticos en el ámbito europeo como avance para mercado laboral Latinoamericano. Los agujeros y carencias de América Latina:

Gobiernos variables: Los cambios constantes de gobierno conlleva la paralización radical de los planes socioeconómicos y origina una mayor inseguridad jurídica. En cambio, Europa generalmente cuenta con gobiernos que se alternan, pero que no replantean o modifican lo fundamental de los planes económicos generales. Existe una mayor continuidad y estabilidad.

Las grandes organizaciones empresariales y financieras han desplegado a su alrededor una red de servilismo gubernamental. En Europa, todavía imperan los mecanismos de equilibrio político.

Desmesuradas diferencias entre clase alta y clase baja. Latinoamérica destaca por sus extremos y por la 
inexistente clase media. En Europa, a pesar de la crisis, no existen esas diferencias tan colosales.

Una izquierda persistente en lograr una renovación y reformulación y que, en el caso de Venezuela, ha sepultado al país. En Europa, la socialdemocracia ha sido uno de los pilares del estado de bienestar sin necesidad de confiscar empresas.

Un subcontinente con un arduo déficit de infraestructuras debido a las largas distancias, a la orografía y a regiones selváticas. Todo eso encarece el tráfico comercial y turístico. En cambio, Europa es un espacio reducido de alta densidad que gracias a las numerosas infraestructuras ha permite disminuir los costes empresariales y ofrecer facilidades turísticas.

5.2.- Latinoamérica un país rico $y$ fructuoso en numerosas variantes modélicas para Europa.

Un continente de 21 millones de kilómetros cuadrados con multitud de recursos naturales, turísticos y ambientales. En cambio, Europa, incluida Rusia, tiene menos recursos minerales e hidrocarburos, y ello, le impide competir o seducir en una suculenta oferta turística de sol y playa.

La clase media emergente supone para las empresas europeas una oportunidad única. En cambio, en Europa, la clase media se ha empobrecido tras la crisis del año 2008. Esto conlleva, al aumento de los contrastes sociales.

Un triángulo demográfico más saludable. El porcentaje de jóvenes en América Latina es el que tenía Europa en los años sesenta. Ahora Europa es un continente que se avejenta, y que cada vez más necesita mano de obra externa para ocupar los puestos de trabajo, que a su vez le causa multitud de controversias sociales, jurídicos, ect.
Latinoamérica es una tierra rica en optimismo con un gran sentido de pertenencia y con intensos deseos de prosperar, mejorar, emprender y hasta unirse. En Europa ha cundido el pesimismo existencial, la desconfianza y la división, como lo demuestra que Gran Bretaña, una gran potencia mundial, va a implementar un referéndum para salir de la UE.

\section{6.- Conclusiones}

En todos los países tanto de Europa como de Latinoamérica, existe una regulación contractual laboral. La principal diferencia radica fundamentalmente en la falta de seguridad jurídica ante tal diversidad de gobiernos quienes no velan por la prosperidad socioeconómica de sus países y por sus ciudadanos en Latinoamérica, y en consecuencia los salarios son irrisorios, falta de garantías y de responsabilidad, de ahí que más de la mitad de los trabajadores, realizan sus labores al margen de la Seguridad Social, mientras que en Europa en base a los principios democráticos y de derecho, protegen tanto los gobiernos, $y$ en especial los sindicatos por los derechos de los trabajadores.

América Latina necesita un cambio estructural donde pueda aumentar la riqueza y formalidad de las relaciones laborales $\mathrm{y}$, además, pueda fortalecer a nivel jurídico la estabilidad y deseables condiciones laborales. Todo ello, va a repercutir en un mejor clima laboral $\mathrm{y}$ social $\mathrm{y}$, por consiguiente, mejores resultados corporativos. Para poder alcanzar todos estos objetivos, es importante el nivel de protección, incentivos, mejoras, subvenciones, reformas legislativas, reformulaciones políticas, instaurar nuevos enfoques 
Relaciones laborales ¿Una realidad estructural, coyuntural o un perjuicio instaurado a nivel mundial?

Bayón Pérez, Jessica y Arenas Falótico, Andrés Jerónimo

estables y sociales que afecten de forma próspera, eficaz y eficiente en el rendimiento empresarial, ya que cuenta con potentes recursos que le puede proporcionar una vital riqueza existencial de esta tierra. Asimismo, resulta vital ir más allá del mercado de trabajo para apuntar hacia el logro de un crecimiento mucho más robusto y vigoroso. Para ello, resulta imprescindible desarrollar e implementar políticas de desarrollo productivo que son una llave para la potenciación del crecimiento superior, sostenible e inclusivo que impulse la creación de empleos formales. Por tanto, se puede afirmar que la inepta gestión de las diferentes políticas sociolaborales de su mercado de trabajo que genera empresas improductivas y unas relaciones laborales totalmente inseguras. Para corroborar esta información, la Organización Internacional de Trabajo (2018) ratifica la elevada tasa de informalidad que alcanza a un $53 \%$, lo que indica que hay cerca de 140 millones de trabajadores en esas condiciones en la región y el $40 \%$ de las personas desempleadas son jóvenes. De las personas jóvenes desempleadas, cada día, seis de ellas encuentran empleos informales. Esta situación se produce en todo el mundo, donde las tasas de desempleo juvenil son dos o tres veces más altas.

Será indispensable promover mejores tasas de crecimiento económico, generar fuentes de empleo, políticas macroeconómicas que gesten nuevos empleos, sobre todo para los jóvenes y programas particulares y específicos que permitan el progreso y evolución positiva de esta generación.

Desde la Unión Europea existe un proyecto del Parlamento europeo ${ }^{22}$ y del Consejo que contiene los desafíos que plantea la evolución del mundo del trabajo, en particular la creciente flexibilización del mercado laboral $y$, mayormente, el incremento de número de formas "atípicas" de trabajo, como el empleo temporal, a tiempo parcial o discontinuo, los contratos de cero horas, el trabajo según demanda y las relaciones de empleo multipartitas. Periódicamente los nuevos modos de empleo no son tan regulares ni tan estables como las relaciones laborales clásicas y tradicionales. Las mismas pueden generar una menor previsibilidad para los trabajadores afectados, con la gran incertidumbre respecto de los derechos y la protección social aplicables. Pueden generar situaciones de gran dependencia y precariedad para el trabajador, que no tiene la seguridad ni la certeza de si podrá trabajar o no y cuándo.

Los avances y evoluciones tecnológicas, la globalización y los cambios demográficos continúan afectando de forma directa en los hábitos de vida y trabajo de las personas europeas. La UE trabaja activamente en la elaboración, reformulación e implantación de políticas y propuestas legislativas para superar estos retos. La legislación laboral europea garantiza niveles mínimos de protección a las personas que viven y se desarrollan personal y profesionalmente en la UE. 
Además, existen normas específicas para proporcionar a la ciudadanía comunitaria una movilidad interna para lograr nuevos empleos y nuevas experiencias laborales conservando sus derechos de seguridad social, como el seguro y las prestaciones de enfermedad.

Finalmente, conjunto de países con necesidades prioritarias de llevar a cabo modificaciones, toma de decisiones adaptadas al contexto social y económico, obteniendo como principal apoyo a la historia de gestión política para no recaer en las mismas fallas.

\section{Referencias Bibliográficas}

Agencia EFE. (26 de febrero de 2019), Francia quiere premiar a las empresas que apuesten por contratos indefinidos. Inversión Finanzas.com. Recuperado de: http://www.finanzas.com/noticias/empleo/20190226/ francia-quiere-premiar-empresas-4000564_age.html

Caro. Carolina (2018), ¿Qué países tienen mayor temporalidad en el empleo? El Boletín. Recuperado de: https://www.elboletin. com/noticia/163605/economia/ que-paises-tienen-mayor-temporalidad-en-el-empleo.html

Céspedes, Teresa. (2018), Desempleo en América Latina se reducirá a 7,8 pct a fines de este año: OIT. Thomsom Reuters. Recuperado de: https://lta.reuters.com/articulo/ latinoamerica-desempleo-idLTAKB$\mathrm{N} 1 \mathrm{OH} 1 \mathrm{QC}$

Commision, European (s.f.), Supporting youth actions in Europe. Obtenido de https://ec.europa.eu/youth/policy/ youth-strategy/employment-entrepreneurship_es
Confederación Sindical de Trabajadores y Trabajadoras de las Américas y la Confederación Sindical Internacional (2013), sobre las Agencias de Trabajo Transitorio (ATT).

Consejo de Redacción. (25 de octubre de 2017), Revista de fomento social. Las reformas laborales: ¡algo más que mercado! Barcelona, España.

David-Rueda, Gonzalo (2016), Diagnostic of Leucoptera coffeella (Lepidoptera: Lyonetiidae) and its parasitoids in the department of Antioquia, Colombia. Rev. Colomb. Entomol, vol.42, n.1, pp.4-11.

Diario Oficial de la Unión Europea. (2018), C 218, 28 de junio de 2019.

Dossantos, Rebecca. (2017), ¿Cuáles son las leyes laborales en Perú? Bizlatinhub. Recuperado de: https:// www.bizlatinhub.com/es/cuales-sonlas-leyes-laborales-en-peru/

Eduardo, Carballo \& Powell, Andrew. (2018), América Latina necesita más inversión y productividad. Estas son las razones. Ideas que cuentan. Recuperado de: https://blogs.iadb. org/ideas-que-cuentan/es/promover-el-crecimiento-a-traves-de-la-inversion-y-la-productividad/

EFE Sau Paulo, (2018), Un 21 \% de los jóvenes en Latinoamérica ni estudia ni trabaja, según informe. El diario. es Recuperado de: https://www. eldiario.es/sociedad/jovenes-Latinoamerica-estudia-trabaja-informe_0_842366710.html

Erico Rentería, Sigmar Malvezzi. (2018), Psicologías organizacionales y de los trabajos - pots. Preguntas desde las realidades actuales del mundo del trabajo en América Latina. Psicología desde el Caribe, Vol. 35 Núm. Especial. 
Relaciones laborales ¿Una realidad estructural, coyuntural o un perjuicio instaurado a nivel mundial?

Bayón Pérez, Jessica y Arenas Falótico, Andrés Jerónimo

Europa Press. (05 de octubre de 2017), Obtenido de Europa Press: https:// www.europapress.es/economia/ laboral-00346/noticia-numero-contratos-indefinidos-ue-crecio-14-primer-trimestre-20171005182905.html

Europa Press (2018), Así se compara el horario laboral español con el de otros países europeos. Europa Press. Recuperado de: https:// www.europapress.es/sociedad/ noticia-asi-compara-horario-laboral-espanol-otros-paises-europeos-20161213135213.html. Recuperado: 5 de abril de 2018

Eurostat, Statistical Office of the European Communities. (2018),

Expansión. Datosmacro.com (2018), Comparar economía países: Francia vs España. Expansión. Datosmacro. com. Recuperado de: https://datosmacro.expansion.com/paises/comparar/francia/espana?sc=XE09

González González, Aurora Patricia. (2018), El contrato de prestación de servicios y el principio de estabilidad laboral constitucional en Colombia. Trabajo de Grado. Universidad Católica de Colombia. Facultad de Derecho. Bogotá, Colombia.

Guerrero, Laura Paola. (2018), Impacto de la calidad de vida laboral en la productividad organizacional (Monografía), Fundación Universidad de América. Recuperado de: http://repository.uamerica.edu.co/ handle/20.500.11839/6877

Hernández, Gustavo \& Piraquive, Gabriel. (28 de mayo de 2018), Salario por hora y contribuciones a la seguridad social. Carta financiera. Recuperado de: http://anif.co/sites/default/files/ archivosgenerales/carta_financiera no.184. pdf\#page $=41$

Hernández, Leandro. (16 de mayo de 2018), Un trabajo para todos y to- das. Termómetro económico y social de América. El País.

Jaime, María del Carmen (2018), El 95\% de las empresas españolas tiene menos de 10 empleados CincoDías. Recuperado de: https://cincodias. elpais.com/cincodias/2018/01/26/ pyme/1516952092_487839.html

Jiménez, José Alejandro. (2016), Necesidad de adoptar componentes axiológicos de justicia y responsabilidad social en la enseñanza y prácticas de aprendizaje que corresponden al área de derecho privado, según el contexto del caribe colombiano. Adelante Ahead. Revista institucional.

Bollain, Julen \& Raventòs, Daniel (2018), La Renta Básica Incondicional ante las limitaciones de las Rentas Mínimas. Sin permiso. Recuperado de: http://www.sinpermiso.info/ textos/la-renta-basica-incondicional-ante-las-limitaciones-de-las-rentas-minimas

Lozano Trujillo, Zulma Alejandra. (20 de abril de 2018), Universidad Militar nueva Granada. La flexibilización laboral en Colombia desde la reforma laboral, ley $\mathbf{7 8 9}$ de 2002: Impacto, evolución y desarrollo de las condiciones laborales.

Maldonado Mera, Betzabé del Rosario; Buenaño Cabrera, José Javier \& Benavides Espinosa, Karla Viviana. (2018), Aproximación a un modelo de gobernanza del Sistema de Educación Superior ecuatoriano. Dialnet. Revista San Gregorio, Vol. 1, pp. 78-83.

Marqués Perales, Ildefonso. (2019), Relevancia de la heterogeneidad socioeconómica: Estudio comparativo entre América Latina y Europa basado en la adaptación del esquema EGP . Depósito digital de los documentos de la Universidad Autónoma de Barcelona. 
Medina, José Alonso, Mendoza, Shila Valeria., Morales, G., \& Vera, Patricia Ángela. (2018), El uso indebido de adendas en contratos bajo la modalidad de asociación público-privada en el Perú: lineamientos para el uso adecuado de adendas. Universidad Peruana de Ciencias Aplicadas (UPC), Lima, Perú. Retrieved from http://hdl.handle.net/10757/623908.

Ministerio de Trabajo, Migraciones y Seguridad Social (26 de abril de 2018), Resumen de últimos datos. Ministerio de Trabajo, Migraciones y Seguridad Social. Recuperado de: http://www.mitramiss.gob.es/es/estadisticas/resumenweb/RUD.pdf

Ministerio de Trabajo Ecuatoriano. (2018), Recuperado de: http://www. trabajo.gob.ec/

Moraes, María Inés. \& Thul, Florencia. (2018), Los salarios reales y el nivel de vida en una economía latinoamericana colonial: montevideo entre 1760-1810. Cambridge University Press, Vol. 36, pp. 185-213.

Manky, Omar. (2017), El lugar importa: Efectos de la movilidad en las estrategias sindicales. Universidad $\mathrm{Na}-$ cional Autónoma de México-Instituto de Investigaciones Sociales. Revista Mexicana de Sociología, Vol. 79, pp. 35-63.

Organización Internacional de Trabajo (2016), Conferencia Internacional de Trabajo, $105 .^{a}$

Pagés-Serra, Carmen (2018), El futuro del trabajo: ¿oportunidad o amenaza para América Latina? El país. Recuperado de: https://elpais.com/ elpais/2018/11/12/planeta_futuro/1542033148_281606.html

RedTransfer. (s.f.), Informe del banco mundial: "el emprendimiento en américa latina: muchas empresas y poca innovación". Redtransfer Noticias.

Rodríguez, Eduardo. (2018), La investigación en comunicación. Madrid: Comunication y Society.

Sánchez, Álvaro. (2018), Las jóvenes ninis son más que los hombres en todos los países de la UE. EI País. Recuperado de: https://elpais. com/sociedad/2019/06/27/actualidad/1561626394_327578.html

Sarasa, Sebastián. (2018), Garantía de ingresos mínimos y empleo. En Universitat Pompeu Fabra (Ed), La revolución digital en España. Impacto y retos sobre el mercado de trabajo y el bienestar. (pp. 213-240), Bellaterra, España: Universitat Autònoma de Barcelona. Recuperado de: https://ddd.uab.cat/record/190325

Tejero Pérez, Aroa. (2018), Revista Internacional de Sociología, Vol 76, No 2. Pobreza laboral en España. Un análisis dinámico. Oviedo: Universidad de Oviedo.

Thomson Reuters. (2018) “Ca-a cancer journal for clinicians" tops the journals in-terms of impact of work they publish. the impact factor of this journal remained 244.585 with 28,839 citations and 0.066030 eigenfactor score for year 2017. Courtesy: Clarivate Analytics

Toharia, Luis. (2002), El modelo español de contratación temporal. Temas laborales: Revista andaluza de trabajo y bienestar social, 117-142.

Tu Europa. Unión Europea. (29 de octubre de 2018), Empleados a través de empresas de trabajo temporal.

UN-CEPAL-OIT. (2018), Coyuntura Laboral en América Latina y el Caribe. El futuro del trabajo en América Latina y el Caribe: antiguas y nuevas formas de empleo y los desafíos para 
Relaciones laborales ¿Una realidad estructural, coyuntural o un perjuicio instaurado a nivel mundial?

Bayón Pérez, Jessica y Arenas Falótico, Andrés Jerónimo

la regulación laboral. Pp. 20-46.

World Bank Group. (2018), Gasto en investigación y desarrollo (\% del PIB), Instituto de Estadística de la
Organización de las Naciones Unidas para la Educación, la Ciencia y la Cultura ( UNESCO ),

- Esta obra está bajo una licencia de Creative Commons Reconocimiento-NoComercial- Compartirlgual 3.0 Unported. http://creativecommons.org/licenses/by-nc-sa/3.0/deed.es_ES 